\title{
Cost matters to small and medium enterprises: a study of Malaysia food and beverage manufacturing
}

\begin{abstract}
This study examines the costs faced by small and medium enterprises (SMEs) involved in food and beverage manufacturing. It investigates the relationship between product value and the costs of producing packaging and related branding. The majority of SMEs in Malaysia have limited funds for product related expenditure. The results from the partial least squares structural equation model (PLS-SEM) show a strong mediation between packaging and branding expenditure towards product value. The food and beverage industries are highly competitive and need to be focused on in more depth. This study is potentially useful for future research directions on both theoretical and practical point of view.
\end{abstract}

Keyword: Branding; Cost; Entrepreneur; Food and beverage products; Small and medium enterprises; SMEs; Packaging; Product value; Partial least squares structural equation model; PLS-SEM; Malaysia 